\title{
Impact of physical activity and bodyweight on health-related quality of life in people with type 2 diabetes
}

This article was published in the following Dove Press journal:

Diabetes, Metabolic Syndrome and Obesity:Targets and Therapy

22 August 2012

Number of times this article has been viewed

\author{
Katharina Eckert \\ Institute of Exercise and Public \\ Health, Faculty of Sport Science, \\ University of Leipzig, Leipzig, \\ Germany
}

Correspondence: Katharina Eckert Institute of Exercise and Public Health, Faculty of Sport Science, University of Leipzig, Jahnallee 59, 04109 Leipzig, Germany

Tel $+4934 \mid 973$ I623

Fax +49 34I-973 I678

Email katharina.eckert@uni-leipzig.de
Purpose: Increasing obesity prevalence rates in the general population are reflected in patients with type 2 diabetes. Health-related quality of life (HRQoL) is negatively affected in patients who are overweight or have diabetes, but physical activity (PA) is proven to have positive side effects on the perceived quality of life. Little is known about the relationship of PA with obesity, diabetes, and HRQoL. Therefore, the objective of the present study was to examine the relationship between HRQoL and PA in type 2 diabetics in association with the severity of overweight.

Methods: This was a cross-sectional multicenter cohort study involving 370 outpatients with type 2 diabetes. Participants completed the SF-36 Health Survey (SF-36 ${ }^{\circledR}$ ) and the Freiburger Questionnaire for Physical Activity (FFkA). Endurance capacity was tested with a $2 \mathrm{~km}$ walking test. $t$-tests, analysis of variance, Pearson's correlation test, and multiple regression analyses were performed.

Results: HRQoL is negatively affected by body mass index (BMI). The results show that patients with type 2 diabetes and grade II obesity (BMI > 35) have a lower HRQoL than overweight patients (BMI 25-29.99) and patients with grade I obesity (BMI 30-35). HRQoL decreases with decreasing PA in all dimensions of the SF-36. PA remains a significant predictor of physical composite summary $(\mathrm{B}=0.09 ; \beta=0.11 ; P<0.05)$, physical function $(\mathrm{B}=0.10 ; \beta=0.13$; $P<0.01)$, mental composite summary $(\mathrm{B}=0.13 ; \beta=0.20 ; P<0.001)$, vitality $(\mathrm{B}=0.15$; $\beta=0.24 ; P<0.001)$, and psychological well-being $(\mathrm{B}=0.11 ; \beta=0.18 ; P<0.01)$ when controlling for age, sex, and BMI.

Conclusion: Because of the strong association between being overweight/obese and several risk factors for morbidity and mortality, reversing the obesity epidemic is an urgent priority. Based upon the results of this study and the available evidence of the efficacy of PA for preventing and treating those who are overweight or obese, health care professionals should continue to stress the importance of PA as a treatment option.

Keywords: diabetes mellitus type 2, health-related quality of life, obesity, physical activity

\section{Introduction}

Being overweight or obese has become a major global health problem over the past several years and will be an enormous economic burden in the future. Their prevalence has grown rapidly in all age groups. ${ }^{1}$ In Germany, $60 \%$ of adult males and $43 \%$ of females are overweight, and approximately one out of four of these adults is obese. Furthermore, $20 \%$ of Germans over the age of 60 have an unhealthy weight condition (body mass index $[\mathrm{BMI}]>30)^{2}$

Additionally, there is a strong epidemiological link between obesity and type 2 diabetes. ${ }^{3,4}$ Ford et $\mathrm{al}^{5}$ found that weight gain over a 10 -year period is strongly associated with an increased risk for type 2 diabetes. Mokdad et $\mathrm{al}^{6}$ conducted a large telephone 
survey in the United States and found that both overweight and obesity were significantly associated with diabetes and several other important health risk factors such as high blood pressure, high cholesterol levels, asthma, arthritis, and fair or poor health status. Overall, the role of obesity in the pathogenesis of non-insulin-dependent diabetes has long been recognized. ${ }^{5}$ Increasing obesity prevalence rates in the general population are reflected in patients with type 2 diabetes. The International Diabetes Federation estimates that the number of people suffering from type 2 diabetes globally will increase from 285 million to 438 million over the next 20 years. $^{7}$

Quality of life is a scientifically proven indicator of the quality of health experienced by a patient. ${ }^{8,9}$ Type 2 diabetes can have a clinically significant impact on the health-related quality of life (HRQoL) of individuals who are overweight or obese ${ }^{8}$ and increased bodyweight can be an important predictor of HRQoL among people with type 2 diabetes, ${ }^{10}$ although these effects are known to be highly variable. ${ }^{11}$ Consequently, HRQoL is emerging as an important outcome in diabetes studies. ${ }^{12}$

Physical activity (PA) is fundamental for preventing and treating type 2 diabetes mellitus in addition to the use of pharmacological and dietary approaches. ${ }^{13}$ Some studies have revealed a positive association between PA level and HRQoL in diabetic patients, ${ }^{10,14-17}$ but others have not. ${ }^{18,19}$ Nicolucci et al ${ }^{17}$ concluded that the results of previous trials investigating the impact of physical exercise on HRQoL in diabetic patients are inconsistent, but the positive effects clearly outnumber the negative effects. Additionally, there is a positive association between PA and the amount of medication required by a patient. ${ }^{20}$ Codogno et $\mathrm{al}^{21}$ determined that type 2 diabetics with higher engagement in PA incur less healthcare expenditure for medication and medical consultations.

Overall, some evidence exists regarding the effectiveness of PA on HRQoL for type 2 diabetes. However, there is a lack of studies on the extent to which being overweight or obese influences HRQoL for type 2 diabetes or on the impact of PA on HRQoL for overweight or obese people suffering from type 2 diabetes.

In terms of target-oriented interventions, it is essential to reach people with special needs in terms of "lived health." 22 Particularly, with regard to allocating and optimizing health care from a patient-oriented, economical, and efficient perspective, it is crucial to identify those at a high risk. Given this issue and demographic changes showing an increasing prevalence of chronic diseases, cross-sectional studies are required to provide evidence on multimorbidity and its impact on patients' HRQoL. Thus far, the issue of the severity of being overweight among type 2 diabetics in association with PA has remained unexplored. Based on prior research, the author hypothesized that, first, HRQoL changes relative to the severity of being overweight and, second, that active participants report better HRQoL than inactive participants, regardless of the severity of their overweight. Therefore, the objective of the present study was to examine the relationship between HRQoL and PA levels in obese type 2 diabetics relative to the severity of overweight.

\section{Methods \\ Design}

This study was a cross-sectional analysis of data from 370 outpatients recruited from German Health Insurance who met the following criteria: (1) diagnosed with type 2 diabetes (glycated haemoglobin $A_{1 c} \geq 7 \%$ based on the American Diabetes Association guidelines ${ }^{23}$ ); (2) insulin-treated or orally medicated; and (3) BMI $>25$. Exclusion criteria were: (1) the presence of diabetes-related complications (eg, unstable and/or uncontrolled cardiac disease, peripheral neuropathy or vascular disease, blindness); (2) dementia or an uncontrolled psychiatric illness; and (3) inability to understand, read, and write German. In addition to personal data, BMI, HRQoL, PA level, and endurance capacity were assessed. The study was approved by the Institutes of Exercise and Public Health, University of Leipzig and Sport and Sport Science, University of Heidelberg, Germany.

\section{Measurements and outcomes HRQoL}

HRQoL was assessed using the SF-36 Health Survey $\left(\mathrm{SF}-36^{\circledR}\right)$ (German Version). ${ }^{24}$ HRQoL reflects a continuum of the quality of health experienced by an individual and represents different domains, including physical and mental dimensions as well as social and personal perceptions and expectations. ${ }^{9}$ The SF-36 is considered well-constructed and valid and has adequate internal consistency reliability (0.81-0.88). ${ }^{10,25,26}$ The 36 items cover a range of categories, including physical function (phyfu); physical role function (role limitations due to physical problems; phyro); bodily pain (pain); general health (genhe); vitality (vita); social function (sofu); emotional role function (role limitations due to emotional problems; emro); and psychological well-being (psyc). ${ }^{10}$ Each category is scored separately from 0 to 100. Higher scores indicate better self-reported HRQoL. Two summary scores exist, the physical composite summary (PCS; 
$\Sigma$ : [phyfu, phyro, pain, genhe]/4) and the mental composite summary (MCS; $\Sigma$ : [vita, sofu, emro, psyc)/4). In this study, the mean Cronbach's alphas for the PCS (0.88) and MCS (0.89) of the SF-36 confirm satisfactory reliability.

\section{Physical fitness (endurance capacity)}

Endurance capacity was assessed by a $2 \mathrm{~km}$ walking test. ${ }^{27}$ The test sums walking time in minutes, pulse rate after $2 \mathrm{~km}, \mathrm{BMI}$, age, and sex into an algorithm to form a walk index (WI). The values of this WI were rated using groups according to five performance categories: >130 ("very good"), 111-130 ("good"), 90-110 (“medium") 70-89 ("weak"), and <70 ("very weak"). This method enables a quick and reliable estimation of the performance level. ${ }^{28}$

\section{Physical activity}

The Freiburger Questionnaire for Physical Activity (FFkA) is a widely used and well-accepted self-administered tool in Germany for measuring health-related PA among adults. ${ }^{29}$ The test collects data through eight questions about basis and leisure time as well as sporting activities (what type, how long, and how often). All data are indexed to one value and converted into $\mathrm{kcal} /$ week. The questionnaire can be used for active and inactive adults aged 18-78. The test-retest reliability of the items varies from $r=0.35$ to $r=0.91 .^{30}$ Cronbach's alphas for the FFkA in the current study were 0.71 for basis activities, 0.71 for leisure activities, and 0.84 for sporting activities.

\section{Formal consent}

All eligible patients were provided with information about the aim and content of the study and gave written consent before participating in the study.

\section{Statistical analysis}

All statistical analyses were performed using SPSS for Windows version 19.0 (IBM Corporation, Armonk, NY).

The characteristics of the participants, HRQoL scores, and PA levels were analyzed using descriptive statistics (means \pm SD). The HRQoL, PA level, and endurance capacity (WI) of the participants were compared through general demographic variables using a $t$-test and analysis of variance (ANOVA). Pearson's correlation test was used to explore bivariate relationships between HRQoL and BMI, WI, duration of diabetes, age, sex, and PA level. Multiple linear regression analyses were conducted by block to ascertain the determinants of HRQoL among overweight and obese type 2 diabetics. The two composite summary scores of
HRQoL, the PCS and the MCS, and the subscales of physical function, vitality, and psychological well-being were chosen as outcome variables. Predictor variables used for the models included age, sex, BMI, and PA. The demographic variables were entered in the first block, BMI was entered in the second block, and PA was entered in the third block.

All results were subsequently checked for effect sizes. ${ }^{31}$ Because multiple comparisons were conducted, an adjustment to the type I error rate was made to preserve the overall alpha level at 0.05 .

\section{Results \\ Sample characteristics}

The participants' mean age was 63.2 years $(\mathrm{SD}=7.6$, range $36-76$ ), and $54.9 \%$ of the sample was female. The average duration of known type 2 diabetes was 10.6 years ( $\pm 6.6,3-36)$. Based on the World Health Organization classification of obesity, ${ }^{32}$ the study sample included $32.9 \%$ overweight (BMI $=25-29.99), 33.7 \%$ obese grade I $(\mathrm{BMI}=30-35)$, and $33.4 \%$ obese grade II $(\mathrm{BMI}>35)$ subjects. Furthermore, $61.3 \%$ of the sample achieved the minimally recommended activity level of $1.000 \mathrm{kcal}$ per week $(32.7 \%$ did not achieve this level, and $6 \%$ did not answer all questions on the FFkA). To establish the level of $1.000 \mathrm{kcal}$, the author was guided by a review of Warburton et $\mathrm{al}^{33}$ on the health benefits of PA.

On average, the sample was low in cardiovascular fitness and showed very poor endurance results. According to criteria by Oja et al, ${ }^{28} 77.7 \%$ were classified as "weak" or "very weak", $11.1 \%$ reached a medium performance level, and $11.2 \%$ proved to be "good" or "very good."

Participants with a BMI of 25-30 (age: 66.2; $\mathrm{SD}=5.5$ ) were older than individuals with a BMI $>35$ (age: 59.8; $\mathrm{SD}=8.7)$, which proved to be significantly different $\left(P<0.001 ; \mathrm{F}=22.780 ; \eta^{2}=0.120\right)$. In the group with BMI $>35$, there were significantly more men than in the two other BMI classes $\left(P<0.01 ; \mathrm{F}=5.045 ; \eta^{2}=0.028\right)$. Significant negative correlations were found between BMI and sex $(\mathrm{r}=-0.097 ; P<0.05)$ and between BMI and age $(\mathrm{r}=-0.359 ; P<0.01)$.

Duration of diagnosis was associated with age $(\mathrm{r}=0.182$; $P<0.05)$ and with physical role function $(\mathrm{r}=-0.148$, $P<0.05)$.

\section{Univariate analyses}

\section{Comparison of HRQoL scales in different BMI classes}

Scores in all HRQoL domains decreased with increasing bodyweight. The group with BMI $>35$ showed the low- 
Table I Mean values of the subscales of SF-36 ${ }^{\circledR}$ separated into overweight (25-29.99), obese grade I (30-35), and obese grade II ( $>35$ ) (SF-36 scores rated with $95 \%$ confidence intervals $[\mathrm{CI}]$ )

\begin{tabular}{|c|c|c|c|c|c|c|}
\hline \multirow[t]{2}{*}{ SF-36 } & \multicolumn{3}{|l|}{ Mean $(95 \% \mathrm{Cl})$} & \multirow[t]{2}{*}{$P$} & \multirow[t]{2}{*}{$\mathbf{F}$} & \multirow[t]{2}{*}{$\eta^{2}$} \\
\hline & BMI 25-29.99 & BMI 30-35 & BMI $>35$ & & & \\
\hline PCS & $68.57(64.44-72.7 I)$ & $61.90(57.85-65.96)$ & $55.06(50.62-59.50)$ & $<0.001$ & 9.971 & 0.088 \\
\hline Physical function & $75.72(72.24-79.21)$ & $64.53(60.42-68.64)$ & $57.38(53.20-61.57)$ & $<0.001$ & 21.327 & 0.136 \\
\hline Physical role function & $70.60(62.87-78.32)$ & $63.62(56.37-70.86)$ & $5 \mathrm{I} .59(43.3 \mathrm{I}-59.87)$ & $<0.01$ & 5.982 & 0.053 \\
\hline Bodily pain & $66.00(61.33-70.67)$ & $61.50(56.56-66.44)$ & $56.33(50.77-61.89)$ & $<0.05$ & 3.537 & 0.042 \\
\hline General health & $59.16(55.73-62.59)$ & $55.27(52.23-58.30)$ & $51.88(48.20-55.55)$ & $<0.05$ & 4.498 & 0.046 \\
\hline MCS & $73.59(69.82-77.35)$ & $66.5 \mathrm{I}(62.50-70.53)$ & $65.03(60.79-69.27)$ & $<0.01$ & 4.945 & 0.040 \\
\hline Vitality & $58.48(55.1 \mathrm{I}-6 \mathrm{I} .86)$ & $52.69(49.49-55.87)$ & $49.36(45.77-52.95)$ & $<0.01$ & 7.168 & 0.066 \\
\hline Social function & $82.00(78.45-85.56)$ & 76.56 (72.35-80.77) & 74.68 (70.0I-79.35) & $<0.05$ & 3.226 & 0.031 \\
\hline Emotional role function & 79.17 (7I.87-86.46) & $70.00(62.14-77.86)$ & 67.71 (59.85-75.57) & 0.093 & 2.391 & 0.017 \\
\hline Psychological well-being & 71.45 (68.28-74.63) & $68.44(65.01-71.87)$ & $66.44(62.6 I-70.26)$ & 0.135 & 2.010 & 0.016 \\
\hline
\end{tabular}

Abbreviations: BMI, body mass index; MCS, mental composite summary; PCS, physical composite summary; SF-36, SF-36 Health Survey.

est mean values in all subscales of the SF-36 (Table 1). Physical health worsened as BMI increased. The differences between the groups in the subscales of physical function $(P<0.001)$, physical role function $(P<0.01)$, bodily pain $(P<0.05)$, general health $(P<0.05)$, vitality $(P<0.01)$, and social function $(P<0.05)$ reached statistical significance. The quality of life PCS $\left(P<0.001, \eta^{2}=0.088\right)$ and MCS $\left(P<0.01, \eta^{2}=0.040\right)$ were lowest in the group with obesity grade II $(\mathrm{BMI}>35)($ Table 1). All patients were under the mean scores of the German norm sample. ${ }^{24}$

Both physical and mental composite summaries of the SF-36 were negatively associated with BMI (PCS: $\mathrm{r}=-0.334, P<0.01 ;$ MCS: $\mathrm{r}=-0.225, P<0.01)$.

\section{Comparison of PA level and endurance capacity}

People with obesity grade II had the weakest endurance capacity (mean $34.9, \mathrm{SD}=69.9 ; 95 \% \mathrm{CI}$ : $18.1-51.8$ ), but the between-group differences (BMI) were not significant $\left(P=0.457, \mathrm{~F}=0.747, \eta^{2}=0.006\right)$. WI was associated with age $(\mathrm{r}=-0.166, P<0.05)$, but not with activity level (kcal/ week) or BMI.

There was a correlation between BMI and activity level ( $\mathrm{r}=-0.157, P<0.05$ ), but BMI groups did not differ in the kcal expended per week by PA $(P=0.318, \mathrm{~F}=1.150$, $\left.\eta^{2}=0.007\right)$.

Comparing the results of the SF-36, PCS, and MCS in association with activity level, the following results were observed: patients who expended less than $1000 \mathrm{kcal}$ per week on PA had lower scores for PCS and MCS (Table 2), independent of BMI. These differences proved to be significant for MCS $(P<0.01, \mathrm{~d}=0.39)$ and for all subscales that represented MCS. PCS was not significant; only one subscale of the PCS, physical function, showed statistical significance
$(P<0.001, \mathrm{~d}=0.38)$. No association was found between PCS and kcal expended per week, except for the subscale of physical function $(\mathrm{r}=0.169, P<0.05)$.

\section{Correlations and multiple regressions}

PA level (kcal/week) showed significant Pearson's correlation coefficients for three dimensions of HRQoL as well as MCS: physical function $(\mathrm{r}=0.169, P<0.05)$, vitality $(\mathrm{r}=0.249$, $P<0.01)$, psychological well-being $(\mathrm{r}=0.179, P<0.05)$, and MCS $(\mathrm{r}=0.211, P<0.01)$. PA level was not correlated with PCS. All subscales of the SF-36 and both composite summaries were negatively correlated with BMI (Table 3).

Regression models, including all predisposing factors (age, sex, BMI, and PA), were significantly predictive of PCS $\left(\mathrm{R}^{2}=0.17, P<0.05\right)$, physical function $\left(\mathrm{R}^{2}=0.23, P<0.01\right), \operatorname{MCS}\left(\mathrm{R}^{2}=0.10, P<0.001\right)$, vitality $\left(\mathrm{R}^{2}=0.14, P<0.001\right)$, and psychological wellbeing $\left(\mathrm{R}^{2}=0.06, P<0.05\right)$. In the models predicting the physical dimensions of HRQoL, BMI predicted more additional variance than PA, whereas PA was the strongest predictor for mental dimensions (Table 4).

\section{Discussion}

Many chronic diseases show negative impacts on HRQoL, similar to obesity and diabetes. ${ }^{1,34-39}$ Furthermore, some studies using the SF-36 revealed that overweight people show a tendency toward lower scores, particularly for PCS, than people of normal weight. The data from this study underscore the fact that the existence of type 2 diabetes and obesity as comorbid factors intensifies their harmful effects on HRQoL. This result seems to be compatible with the literature, taking into account the additional burden that diabetes and obesity bring to affected people. 
Table 2 Mean values of SF- $36^{\circledR}$ subscales separated by physical activity level (recommended PA guidelines $=1000 \mathrm{kcal} /$ week)

\begin{tabular}{|c|c|c|c|c|c|}
\hline \multirow[t]{2}{*}{ SF-36 } & \multicolumn{2}{|l|}{ Mean (SD) } & \multirow[t]{2}{*}{$P$} & \multirow[t]{2}{*}{$t$} & \multirow[t]{2}{*}{ d } \\
\hline & $<1000$ kcal n $=115$ & $>1000 \mathrm{kcal} \mathrm{n}=231$ & & & \\
\hline PCS & $59.82(23.39)$ & $64.60(22.09)$ & 0.064 & -1.861 & 0.22 \\
\hline Physical function & $61.61(25.02)$ & $70.28(20.88)$ & $<0.001$ & -3.613 & 0.38 \\
\hline Physical role function & $61.28(43.38)$ & $65.04(40.21)$ & 0.419 & -0.809 & 0.09 \\
\hline Bodily pain & $60.09(27.57)$ & $63.81(28.06)$ & 0.213 & -1.246 & 0.13 \\
\hline General health & $53.86(17.05)$ & $57.57(18.70)$ & 0.063 & -1.868 & 0.21 \\
\hline MCS & $63.99(22.35)$ & $71.97(18.86)$ & $<0.01$ & -3.443 & 0.39 \\
\hline Vitality & $49.68(20.15)$ & $56.96(16.83)$ & $<0.001$ & -3.670 & 0.39 \\
\hline Social function & $75.28(23.67)$ & $80.90(21.47)$ & $<0.05$ & -2.185 & 0.25 \\
\hline Emotional role function & $67.22(42.78)$ & $76.99(38.25)$ & $<0.05$ & -2.185 & 0.24 \\
\hline Psychological well-being & $65.92(20.2 I)$ & $71.12(16.75)$ & $<0.01$ & -2.607 & 0.28 \\
\hline
\end{tabular}

Abbreviations: Kcal, kilocalorie (large calorie); MCS, mental composite summary; PA, physical activity; PCS, physical composite summary; SD, standard deviation; SF-36, SF-36 Health Survey.

This is the first study to examine specifically the role of the severity of obesity in type 2 diabetes on PA and HRQoL. The results show that patients with type 2 diabetes and grade II obesity (BMI $>35$ ) have lower HRQoL than overweight patients (BMI 25-29.99) and patients with obesity grade I (BMI 30-35).

People with this health condition are at high risk in terms of morbidity, mortality and health care costs. ${ }^{40-42}$ It is clear that regular PA can improve quality of life in people with chronic illnesses. ${ }^{43-46} \mathrm{PA}$ has both direct and indirect effects on the relationship between diabetes and HRQoL. ${ }^{47}$ In the present study, obese patients who were physically active had higher SF-36 scores than inactive obese patients. It seems

Table 3 Pearson's correlation matrix $(n=330)$

\begin{tabular}{|c|c|c|c|c|c|c|}
\hline Variable & I & 2 & 3 & 4 & 5 & 6 \\
\hline I. Age & - & & & & & \\
\hline 2. Sex & $0.107^{*}$ & - & & & & \\
\hline 3. BMI & $-0.359 * *$ & $-0.097 *$ & - & & & \\
\hline 4. $\mathrm{PA}$ & $-0.252^{* *}$ & $0.191 *$ & $-0.157^{*}$ & - & & \\
\hline 5. WI & $-0.0166 * *$ & $-0.395 * *$ & -0.090 & -0.034 & - & \\
\hline 6. DD & $0.182^{*}$ & 0.083 & 0.035 & 0.044 & -0.106 & - \\
\hline 7. PCS & -0.071 & 0.055 & $-0.334 * *$ & 0.100 & 0.082 & -0.091 \\
\hline 8. Phyfu & -0.091 & 0.096 & $-0.380 * *$ & $0.169 *$ & $0.128^{*}$ & -0.121 \\
\hline 9. Phyro & -0.074 & 0.027 & $-0.25 \mathrm{I} * *$ & 0.049 & 0.035 & $-0.148 *$ \\
\hline 10. Pain & -0.054 & $0.101 *$ & $-0.25 \mathrm{I} * *$ & 0.051 & 0.079 & -0.034 \\
\hline II. Genhe & 0.058 & -0.079 & $-0.226 * *$ & 0.022 & 0.080 & -0.040 \\
\hline 12. MCS & 0.032 & 0.077 & $-0.225 * *$ & $0.211 * *$ & 0.062 & 0.008 \\
\hline 13. Vita & $0.113^{*}$ & 0.071 & $-0.291 * *$ & $0.249 * *$ & 0.073 & -0.022 \\
\hline 14. Sofu & 0.061 & -0.011 & $-0.213^{* *}$ & 0.143 & 0.077 & 0.044 \\
\hline 15. Emro & -0.042 & 0.065 & $-0.138 * *$ & 0.130 & 0.015 & -0.026 \\
\hline 16. Psyc & 0.101 & 0.087 & $-0.163^{* *}$ & $0.179 *$ & 0.034 & 0.036 \\
\hline
\end{tabular}

Notes: $* P<0.05$ level; $* * P<0.01$ level (2-tailed).

Abbreviations: BMI, body mass index; DD, diagnosed with diabetes; Emro, emotional function; Genhe, general health; MCS, mental composite summary; PA, physical activity; Pain, bodily pain; PCS, physical composite summary; Phyfu, physical function; Phyro, physical role function; Psyc, psychological well-being; Sofu, social function; Vita, vitality; WI, walk test index. that "physical activity may $[\ldots]$ reduce the likelihood of acquiring additional chronic conditions. ${ }^{, 47}$ Furthermore, next to diet, PA is the primary factor that can be used to reduce excessive body weight and stabilize a healthy weight level ${ }^{48-51}$ and is a catalyst for other bodily processes. PA reduces major cardiometabolic and vascular (as well as other) risk factors for direct complications, supports glycemic control, and enhances emotional well-being. ${ }^{52-55}$

It is important to note that HRQoL decreases with decreasing PA in all dimensions of the SF-36, particularly in the psychosocial subscales. A possible explanation could be that higher BMI may be accompanied by depressive symptoms, and this effect is aggravated by low cardiovascular capacity. ${ }^{56}$ This is important for the influence of diabetes and the appearance of anxiety and depression. ${ }^{11}$

In the current study, BMI did not affect the impact of PA on HRQoL. According to the results of Häkkinen et al, ${ }^{57}$ these findings are relevant to patients with pre-diabetes also. Kruger et $a l^{58}$ suggest that this is a valuable indicator that activity programs should be implemented into standard medical care for obese patients as well as for diabetics. Although some exercise programs exist, it remains challenging to motivate individuals to change their lifestyle habits. Therefore, it is recommended that further exercise programs should include patient education and self-management skills to sustainably enhance patients' activity levels. ${ }^{59,60}$ There is substantial evidence that effectiveness is enhanced when interventions fit easily into people's everyday lives, include awarenessraising tools (eg, accelerometers to monitor PA), and involve various behavioral strategies, such as motivational interviewing and problem-solving techniques. ${ }^{61}$ Additionally, a combination of group and individual sessions offers a more collaborative approach and facilitates a focus on people's individual preferences. What is more, the mixture 
Table 4 Variables predicting PCS, physical function, MCS, vitality, and psychological well-being of HRQoL (multiple regression of significant predictors, in blocks)

\begin{tabular}{|c|c|c|c|c|c|c|c|c|c|}
\hline \multirow[t]{2}{*}{ Variables } & \multicolumn{3}{|c|}{ Model I } & \multicolumn{3}{|l|}{ Model 2} & \multicolumn{3}{|c|}{ Model 3} \\
\hline & B & SE B & $\beta$ & B & SE B & $\beta$ & B & SE B & $\beta$ \\
\hline \multicolumn{10}{|l|}{ PCS } \\
\hline Age & -0.24 & 0.17 & -0.08 & -0.68 & 0.17 & $-0.23 * * *$ & -0.67 & 0.17 & $-0.22 * * *$ \\
\hline Sex & 3.16 & 2.56 & 0.07 & 2.38 & 2.37 & 0.05 & 2.16 & 2.36 & 0.05 \\
\hline BMI & & & & $-1.6 \mid$ & 0.22 & $-0.41 * * *$ & -1.59 & 0.21 & $-0.4 I^{* * *}$ \\
\hline PA & & & & & & & 0.09 & 0.04 & $0.11 *$ \\
\hline$R^{2}$ & 0.01 & & & 0.16 & & & 0.17 & & \\
\hline $\mathrm{F}$ for change in $\mathrm{R}^{2}$ & 1.56 & & & $55.95 * * *$ & & & $4.15^{* * * *}$ & & \\
\hline \multicolumn{10}{|l|}{ Physical function } \\
\hline Age & -0.32 & 0.16 & -0.10 & -0.83 & 0.16 & $-0.27 * * *$ & -0.83 & 0.16 & $-0.27 * * *$ \\
\hline Sex & 4.33 & 2.45 & 0.09 & 3.05 & 2.20 & 0.07 & 2.72 & 2.18 & 0.06 \\
\hline BMI & & & & -1.85 & 0.80 & $-0.48 * * *$ & -1.85 & 0.20 & $-0.47 * * *$ \\
\hline PA & & & & & & & 0.10 & 0.04 & $0.13 * *$ \\
\hline $\mathrm{R}^{2}$ & 0.02 & & & 0.21 & & & 0.23 & & \\
\hline$F$ for change in $R^{2}$ & $3.10 *$ & & & $87.73 * * *$ & & & 7.60 *** & & \\
\hline \multicolumn{10}{|l|}{ MCS } \\
\hline Age & 0.02 & 0.15 & 0.01 & -0.21 & 0.16 & -0.08 & -0.21 & 0.16 & -0.08 \\
\hline Sex & 4.91 & 2.34 & $0.12^{*}$ & 4.61 & 2.21 & $0.11^{*}$ & 4.06 & 2.24 & 0.10 \\
\hline BMI & & & & -0.84 & 0.21 & $-0.24 * *$ & $-0.8 \mathrm{I}$ & 0.20 & $-0.23 * *$ \\
\hline PA & & & & & & & 0.13 & 0.04 & $0.20 * * *$ \\
\hline $\mathrm{R}^{2}$ & 0.02 & & & 0.07 & & & 0.10 & & \\
\hline$F$ for change in $R^{2}$ & 2.29 & & & $\left.16.7\right|^{* * *}$ & & & $13.20 * * *$ & & \\
\hline \multicolumn{10}{|l|}{ Vitality } \\
\hline Age & 0.26 & 0.14 & 0.11 & 0.03 & 0.14 & 0.01 & 0.04 & 0.14 & 0.02 \\
\hline Sex & 2.92 & 2.02 & 0.08 & 2.35 & 1.96 & 0.06 & 1.84 & 1.91 & 0.05 \\
\hline BMI & & & & -0.84 & 0.18 & $-0.27 * * *$ & $-0.8 \mathrm{I}$ & 0.17 & $-0.24 * * *$ \\
\hline PA & & & & & & & 0.15 & 0.03 & $0.24 * * *$ \\
\hline$R^{2}$ & 0.02 & & & 0.08 & & & 0.14 & & \\
\hline$F$ for change in $R^{2}$ & $3.34 *$ & & & $22.28 * * *$ & & & $22.03 * * *$ & & \\
\hline \multicolumn{10}{|c|}{ Psychological well-being } \\
\hline Age & 0.23 & 0.14 & 0.09 & 0.11 & 0.14 & 0.05 & 0.12 & 0.14 & 0.05 \\
\hline Sex & 2.91 & 2.03 & 0.08 & 2.70 & 2.02 & 0.07 & 2.30 & 2.00 & 0.06 \\
\hline BMI & & & & $-0.4 \mathrm{I}$ & 0.18 & $-0.13^{*}$ & -0.39 & 0.18 & $-0.13^{*}$ \\
\hline PA & & & & & & & 0.11 & 0.03 & $0.18 * *$ \\
\hline$R^{2}$ & 0.02 & & & 0.03 & & & 0.06 & & \\
\hline$F$ for change in $R^{2}$ & 2.71 & & & $4.98 *$ & & & $11.32 *$ & & \\
\hline
\end{tabular}

Notes: $* P<0.05$ level; $* * P<0.0$ I level; $* * * P<0.00$ I level (2-tailed).

Abbreviations: BMI, body mass index; HRQoL, health-related quality of life; MCS, mental composite summary; PA, physical activity; PCS, physical composite summary.

of group and individual training may be a cost-effective delivery strategy. ${ }^{62}$

This investigation was not without limitations. First, the calculated activity levels are very high for this group of patients in relation to their endurance capacity. A plausible reason may be that the selected questionnaire (FFkA) was not feasible for our sample. The patients may have misclassified their activity level, a phenomenon that is well known for self-administered measurements of PA. Second, BMI as a measure of the prevalence of overweight and obesity has limitations. BMI does not differentiate between fat levels and muscle levels. Therefore, it is not appropriate to estimate health hazards. Nevertheless, we chose BMI as a measurement because it is easy to estimate and is cost-effective. Further studies should substantiate BMI by analyzing body composition or considering waist circumference, which has been shown to be a good predictor of cardiometabolic risk. ${ }^{63,64}$ Third, this study cannot determine whether the association between PA level and HRQoL can be explained via causal pathways. However, the results of the regression analyses and the interactions between obesity and $\mathrm{kcal} /$ week spent on PA are initial indicators that the negative effect of high BMI on HRQoL may be moderated in part by an active lifestyle. Further studies are necessary to support the current findings, and additional studies must be conducted to examine the effects of lifestyle interventions on HRQoL 
in overweight and obese people with type 2 diabetes. ${ }^{10,65} \mathrm{We}$ are currently analyzing longitudinal data to determine the effects of a behavioral-oriented exercise intervention on PA, endurance capacity, and HRQoL in overweight and obese patients with type 2 diabetes. This and further studies may help to explain the complex relationships between PA, type 2 diabetes, and excessive bodyweight.

\section{Conclusion}

The study sample of obese type 2 diabetics confirms that physically active patients have better HRQoL than inactive patients, regardless of BMI category. Physical inactivity has a strong impact on patients' self-administered HRQoL. Overall, our participants performed very poorly on the endurance capacity test. The new focus on patient-centred medical care requires better understanding of individuals' constitution, including cardiovascular fitness, PA level, and their role in meeting patients' needs. ${ }^{66}$

This study includes a grouping that is at high risk for comorbidity and mortality, but that has not been an adequate subject of previous research. Based on evidence of the efficacy of PA for preventing and treating obese diabetics and based on the enormous risk exposure of this group, persons responsible for health care should integrate behavioraloriented exercise programs into standard medical care.

According to Codogno et $\mathrm{al}^{21}$ and Sawatzky et al, ${ }^{47} \mathrm{PA}$ is a proven but remarkably underused health promotion modality.

\section{Acknowledgments}

The author would like to thank G Huber, University of Heidelberg, Institute of Sport and Sport Science for support provided for data collection. The study was funded by a grant from the German Association of Health-related Sport and Sport Therapy (DVGS eV).

\section{Disclosure}

The author reports no conflicts of interest in this work.

\section{References}

1. Ucan O, Ovayolu N. Relationship between diabetes mellitus, hypertension and obesity, and health-related quality of life in Gaziantep, a central south-eastern city in Turkey. JCN. 2010;19:2511-2519.

2. Federal Statistical Office. Mikrozensus - Fragen zur Gesundheit. Körpermaße der Bevölkerung [Microcensus - Questions About Health. Body Dimensions]. Statistisches Bundesamt: Wiesbaden; 2001. German.

3. Hu FB, Manson JE, Stampfer MJ, et al. Diet, lifestyle, and the risk of type 2 diabetes mellitus in women. N Engl J Med. 2001;345:790-797.

4. Rana JS, Li TY, Manson JE, Hu FB. Adiposity compared with physical inactivity and risk of type 2 diabetes in women. Diabetes Care. 2007;30: $53-58$.
5. Ford ES, Williamson DF, Liu S. Weight change and diabetes incidence: findings from a national cohort of US adults. Am J Epidemiol. 1997; 146(3):214-222.

6. Mokdad AH, Ford ES, Bowman BA, et al. Prevalence of obesity, diabetes, and obesity-related health risk factors, 2001. JAMA. 2003;289(1): 76-79.

7. Rathmann W. Epidemiologie des Diabetes [Epidemiology of diabetes] Der Diabetologe. 2010;6:169. German.

8. Wadell PE. Quality of life of patients with diabetes mellitus. An overview of research in primary health care in the Nordic countries. Scan J Prim Health Care. 2005;23:68-74.

9. Sato I, Higuchi A, Yanagisawa T, et al. Factors influencing self- and parent-reporting health-related quality of life in children with brain tumors. Qual Life Res. 2012; doi:10.1007/s11136-012-0137-3.

10. Bennett WL, Ouyang P, Wu AW, Barone BB, Stewart KJ. Fatness and fitness: how do they influence health-related quality of life in type 2 diabetes mellitus? Health Qual Life Outcomes. 2008;4(6):110.

11. Peyrot M, Rubin RR. Levels and risks of depression and anxiety symptomatology among diabetic adults. Diabetes Care. 1997;20: 585-590.

12. Haasan MK, Joshi AV, Madhavan SS, Amonkar MM. Obesity and health-related quality of life: a cross-sectional analysis of the US population. Int J Obes Relat Metab Disord. 2003;27(10):1227-1232.

13. Umpierre D, Ribeiro PA, Kramer CK, et al. Physical activity advice only or structured exercise training and association with $\mathrm{HbA}_{\mathrm{lc}}$ levels in type 2 diabetes: a systematic review and meta-analysis. JAMA. 2011; 305(17):1790-1799.

14. Smith DW, McFall SL. The relationship of diet and exercise for weight control and the quality of life gap associated with diabetes. J Psychosom Res. 2005;59(6):385-392.

15. Chyun DA, Mellus GD, Katten DM, et al. The association of psychological factors, physical activity, neuropathy, and quality of life in type 2 diabetes. BRN. 2006;7(4):279-288.

16. Imayama I, Plotnikoff RC, Courneya KS, Johnson JA. Determinants of quality of life in adults with type 1 and type 2 diabetes. Health Qual Life Outcomes. 2011;19(9):115.

17. Nicolucci A, Balducci S, Cardelli P, et al; Italian Diabetes Exercise Study Investigators. Relationship of exercise volume to improvements of quality of life with supervised exercise training in patients with type 2 diabetes in a randomised controlled trial: the Italian Diabetes and Exercise Study (IDES). Diabetologia. 2012;55(3):579-588.

18. Reid RD, Tulloch HE, Sigal RJ, et al. Effects of aerobic exercise, resistance exercise or both, on patient-reported health status and well-being in type 2 diabetes mellitus: a randomised trial. Diabetologia. 2012;53(4): 632-640.

19. Toobert DJ, Glasgow RE, Strycker LA, et al. Biologic and quality-of-life outcomes from the Mediterranean Lifestyle Program: a randomized clinical trial. Diabetes Care. 2003;26(8):2288-2293.

20. Bertoldi AD, Hallal PC, Barros AJ. Physical activity and medicine use: evidence from a population-based study. BMC Public Health. 2006; doi:10.1186/1471-2458-6-224.

21. Codogno JS, Fernandes RA, Sarti FM, Freitas Júnior IF, Monteiro HL. The burden of physical activity on type 2 diabetes public healthcare expenditures among adults: a retrospective study. BMC Public Health. 2011;11:275.

22. Bullinger M. Erfassung der gesundheitsbezogenen Lebensqualität mit dem SF-36 Health-Survey [Recording the health-related quality of life with the SF-36 Health Survey]. In: Bundesgesundheitsblatt Gesundheitsforschung Gesundheitsschutz. 2000;43(3):190-197. German.

23. American Diabetes Association. Standards of medical care in diabetes - 2010. Diabetes Care. 2010;33(Supp 1):S11-S61.

24. Bullinger M, Kichberger I. SF-36 Fragebogen zum Gesundheitszustand. Handanweisung [SF-36 Questionnaire on Health Conditions. Handbook]. Götting: Hogrefe; 1998. German.

25. Trief PM, Wade MJ, Pine D, Weinstock RS. A comparison of healthrelated quality of life of elderly and younger insulin-treated adults with diabetes. Age Ageing. 2003;32:613-618. 
26. McHorney CA, Ware JE Jr, Lu JF, Sherbourne CD. The MOS 36-item Short Form Health Survey (SF-36), III. Tests of data quality, scaling assumptions, and reliability across diverse patient groups. Medical Care. 1994;32:40-66.

27. Boes K, Wydra G, Karisch G. Gesundheitsförderung durch Bewegung, Spiel und Sport. Ziele und Methoden des Gesundheitssports in der Klinik [Health Promotion Through Exercise, Games and Sports. Objectives and Methods of Sport in Health Clinics]. Erlangen: perimed-FachbuchVerl-Ges; 1992. German.

28. Oja P, Laukkanen R, Pasanen M, Tyry T, Vuori I. A 2-km walking test for assessing the cardiorespiratory fitness of healthy adults. Int J Sports Med. 1992;12(4):356-362.

29. Frey I, Berg A, Grathwohl D, Keul J. Freiburger Fragebogen zur körperlichen Aktivität - Entwicklung, Prüfung und Anwendung [Freiburg Questionnaire of physical activity - development, evaluation and application]. Soz Praventivmed. 1999;44(2):55-64. German.

30. Schlicht W, Brand R. Körperliche Aktivität, Sport und Gesundheit [Physical Activity, Sport and Health]. Weinheim and München: Juventa; 2007.

31. Cohen J. A power primer. Psychol Bull. 1992;122:155-159.

32. [No authors listed]. Obesity: preventing and managing the global epidemic. Report of a WHO consultation. World Health Organ Tech Rep Ser. 2000;894:i-xii, 1-253.

33. Warburton DE, Nicol CW, Bredin SS. Health benefits of physical activity: the evidence. CMAJ. 2006;174(6):801-809.

34. Sach TH, Barton GR, Doherty M, Muir KR, Jenkinson C, Avery AJ. The relationship between body mass index and health-related quality of life: comparing the EQ-5D, EuroQol VAS and SF-6D. Int $J$ of Obes (Lond). 2007;31:189-196.

35. Erickson SR, Williams BC, Gruppen LD. Relationship between symptoms and health-related quality of life in patients treated for hypertension. Pharmacotherapy. 2004;24:344-350.

36. Ross KM, Milsom VA, Rickel KA, et al. The contribution of weight loss and increased physical fitness to improvements in health-related quality of life. Eat Behav. 2009;10:84-88.

37. Jayasinghe UW, Proudfoot J, Barton CA, et al. Quality of life of Australian chronically-ill adults: patient and practice characteristics matter. Health Qual Life Outcomes. 2009;7:50.

38. Guh DP, Zhang W, Bansback N, Amarsi Z, Birmingham CL, Anis AH. The incidence of co-morbidities related to obesity and overweight. A systematic review and meta-analysis. BMC Public Health. 2009; 9:88.

39. Han JH, Park HS, Shin CL, et al. Metabolic syndrome and quality of life (QOL) using generalised and obesity-specific QOL scales. Int $J$ Clin Pract. 2009;63:735-741.

40. Tunceli O, Wade R, Gu T, Bouchard JR, Aagren M, Luo W. Cost of diabetes: comparison of disease-attributable and matched cohort cost estimation methods. Curr Res Med Opin. 2010;26(8):1827-1834.

41. Davis WA, Knuiman MW, Hendrie D, Davis TM. The obesity-driven rising costs of type 2 diabetes in Australia: projections from the Fremantle Diabetes Study. Intern Med J. 2006;36(3):155-161.

42. Testa MA, Simonsen DC. Health economic benefits and quality of life during improved glycemic control in patients with type 2 diabetes mellitus a randomized, controlled clinical trial. JAMA. 1998;280(17): 1490-1496.

43. Conn VS, Hafdahl AR, Brown LM. Meta-analysis of quality-of-life outcomes from physical activity interventions. Nurs Res. 2009;58: $175-183$.

44. Abell JE, Hootman JM, Zack MM, Moriarty D, Helmick CG. Physical activity and health related quality of life among people with arthritis. J Epidemiol Community Health. 2005;59(5):380-385.

45. Brown DW, Balluz LS, Heath GW, et al. Associations between recommended levels of physical activity and health-related quality of life. Findings from the 2001 Behavioral Risk Factor Surveillance System (BRFSS) Survey. Prev Med. 2003;37(5):520-528.
46. Pedersen SS, Ong AT, Sonnenschein K, Serruys PW, Erdman RA, van Domburg RT. Type D Personality and diabetes predict the onset of depressive symptoms in patients following percutaneous coronary intervention. Am Heart J. 2006;151:367.e1-367.e6.

47. Sawatzky R, Liu-Ambrose T, Miller WC, Marra CA. Physical activity as a mediator of the impact of chronic conditions on quality of life in older adults. Health Qual Life Outcomes. 2007;5:68.

48. Fogelholm M. Physical activity, fitness and fatness: relations to mortality, morbidity and disease risk factors. A systematic review. Obes Rev. 2012;11(3):202-221.

49. Han TS, Tajar A, Lean ME. Obesity and weight management in the elderly. Br Med Bull. 2011;97:169-196.

50. Manzoni GM, Villa V, Compare A, et al. Short-term effects of a multidisciplinary cardiac rehabilitation programme on psychological wellbeing, exercise capacity and weight in a sample of obese in-patients with coronary heart disease: A practical-level study. Psychol Health Med. 2011;16(2):178-189.

51. Nield L, Summerbell CD, Hooper L, Whittaker V, Moore H. Dietary advice for the prevention of type 2 diabetes mellitus in adults. Cochrane Database Syst Rev. 2008;16(3):CD005102.

52. Craft LL, Perna FM. The benefits of exercise for the clinically depressed. Prim Care Companion J Clin Psychatry. 2004;6(3):104-111.

53. Pedersen BK, Saltin B. Evidence for prescribing exercise as therapy in chronic disease. Scand J Med Sci Sports. 2006;16(Suppl 1):3-63.

54. Goodpaster BH, DeLang JP, Otto AD, et al. Effects of diet and physical activity interventions on weight loss and cardiometabolic risk factors in severely obese adults. JAMA. 2010;304(16):1795-1802.

55. Boulé NG, Haddad E, Kenny GP, Wells GA, Sigal RJ. Effects of exercise on glycemic control and body mass in type 2 diabetes mellitus: a meta-analysis of controlled clinical trials. JAMA. 2001;286: 1218-1227.

56. Rejeski WJ, Lang W, Neiberg RH, et al. Correlates of health-related quality of life in overweight and obese adults with type 2 diabetes. Obesity (Silver Spring). 2006;14(5):870-883.

57. Häkkinen A, Kukka A, Onatsu T, et al. Health-related quality of life and physical activity in persons at high risk for type 2 diabetes. Disabil Rehabil. 2009;31(10):799-805.

58. Kruger J, Bowles HR, Jones DA, Ainsworth BE, Kohl HW 3rd. Health-related quality of life, BMI and physical activity among US adults ( $\geq 18$ years): National Physical Activity and Weight Loss Survey, 2002. Int J Obes (Lond). 2007;31(2):321-327

59. Unick JL, Beavers D, Jakicic JM, et al. Effectiveness of lifestyle interventions for individuals with severe obesity and type 2 diabetes: results from the Look AHEAD trial. Diabetes Care. 2012;34(10): 2152-2157.

60. Lippke S, Ziegelmann J, Schwarzer R. Behavioral intentions and action plans promote physical exercise: A longitudinal study with orthopaedic rehabilitation patients. J Sport Exercise Psy. 2004;26:470-483.

61. Rejeski WJ, Ip EH, Bertoni AG, et al; Look AHEAD Research Group. Lifestyle change and mobility in obese adults with type 2 diabetes. N Engl J Med. 2012;366:1209-1217.

62. Foy CG, Lewis CE, Hairston KG, et al; Look AHEAD Research Group. Intensive lifestyle intervention improves physical function among obese adults with knee pain: findings from the Look AHEAD Trial. Obesity. 2011;19(1):83-93.

63. Pouliot MC, Després JP, Lemieux S, et al. Waist circumference and abdominal sagittal diameter: best simple anthropometric indices of abdominal visceral adipose tissue accumulation and related cardiovascular risk in men and women. Am J Cardiol. 1994;73:460-468.

64. Klein S, Allison DB, Heymsfield SB, et al. Waist circumference and cardiometabolic risk: a consensus statement from shaping America's health: Association for weight management and obesity prevention; NAASO, The Obesity Society; the American Society for Nutrition; and the American Diabetes Association. Am J Clin Nutr. 2007;85(5): $1197-1202$. 
65. Zhang X, Norris SL, Chowdhury FM, Gregg EW, Zhang P. The effects of interventions on health-related quality of life among persons with diabetes: a systematic review. Med Care. 2007;45(9):820-834.
66. Hu J, Wallace DC, Tesh AS. Physical activity, obesity, nutritional health and quality of life in low-income hispanic adults with diabetes. J Community Health Nurs. 2010;27(2):70-83.

\section{Publish your work in this journal}

Diabetes, Metabolic Syndrome and Obesity: Targets and Therapy is an international, peer-reviewed open-access journal committed to the rapid publication of the latest laboratory and clinical findings in the fields of diabetes, metabolic syndrome and obesity research. Original research, review, case reports, hypothesis formation, expert opinion and commentaries are all considered for publication. The manuscript management system is completely online and includes a very quick and fair peer-review system, which is all easy to use. Visit http://www.dovepress.com/testimonials.php to read real quotes from published authors.

Submit your manuscript here: http://www.dovepress.com/diabetes-metabolic-syndrome-and-obesity-targets-and-therapy-journal 